\title{
ARTICLE \\ Operant self-stimulation of thalamic terminals in the dorsomedial striatum is constrained by metabotropic glutamate receptor 2
}

\author{
Kari A. Johnson $\mathbb{D}^{1,3}$, Lucas Voyvodic ${ }^{1}$, Gabriel C. Loewinger $\mathbb{D}^{2}$, Yolanda Mateo ${ }^{1}$ and David M. Lovinger ${ }^{1}$
}

\begin{abstract}
Dorsal striatal manipulations including stimulation of dopamine release and activation of medium spiny neurons (MSNs) are sufficient to drive reinforcement-based learning. Glutamatergic innervation of the striatum by the cortex and thalamus is a critical determinant of MSN activity and local regulation of dopamine release. However, the relationship between striatal glutamatergic afferents and behavioral reinforcement is not well understood. We evaluated the reinforcing properties of optogenetic stimulation of thalamostriatal terminals, which are associated with vesicular glutamate transporter 2 (Vglut2) expression, in the dorsomedial striatum (DMS), a region implicated in goal-directed behaviors. In mice expressing channelrhodopsin-2 (ChR2) under control of the Vglut2 promoter, optical stimulation of the DMS reinforced operant lever-pressing behavior. Mice also acquired operant selfstimulation of thalamostriatal terminals when ChR2 expression was virally targeted to the intralaminar thalamus. Stimulation trains that supported operant responding evoked dopamine release in the DMS and excitatory postsynaptic currents in DMS MSNs. Our previous work demonstrated that the presynaptic $\mathrm{G}$ protein-coupled receptor metabotropic glutamate receptor 2 ( $\left.\mathrm{mGlu}_{2}\right)$ robustly inhibits glutamate and dopamine release induced by activation of thalamostriatal afferents. Thus, we examined the regulation of thalamostriatal self-stimulation by $\mathrm{mGlu}_{2}$. Administration of an $\mathrm{mGlu}_{2 / 3}$ agonist or an $\mathrm{mGlu}_{2}$-selective positive allosteric modulator reduced self-stimulation. Conversely, blockade of these receptors increased thalamostriatal self-stimulation, suggesting that endogenous activation of these receptors negatively modulates the reinforcing properties of thalamostriatal activity. These findings demonstrate that stimulation of thalamic terminals in the DMS is sufficient to reinforce a self-initiated action, and that thalamostriatal reinforcement is constrained by $\mathrm{mGlu}_{2}$ activation.
\end{abstract}

Neuropsychopharmacology (2020) 45:1454-1462; https://doi.org/10.1038/s41386-020-0626-y

\section{INTRODUCTION}

The dorsal striatum is a critical structure supporting reinforcement learning [1]. Classical intracranial self-stimulation (ICSS) studies in rats identified stimulation sites throughout the dorsal striatum that support operant responding [2,3]. More recently, application of optogenetic techniques demonstrated that selective stimulation of nigrostriatal dopamine neurons is sufficient to support reinforcement learning [4, 5]. In addition, activation of striatal projection neurons (medium spiny neurons, MSNs) in either the medial (DMS) or lateral (DLS) subregion of the dorsal striatum reinforces actions [6-8]. Because MSN activity critically depends on glutamatergic inputs, it is necessary to consider how glutamatergic projections to the striatum support reinforcement learning. Currently, whether activation of glutamatergic inputs to the dorsal striatum is sufficient to drive reinforcement remains unclear.

MSNs receive glutamatergic inputs from cortical and thalamic regions [9-11]. Whereas corticostriatal involvement in reinforcement learning has been studied extensively [12], few studies have examined the contributions of thalamic projections [13]. Inputs to the striatum from rostral intralaminar thalamic nuclei and from the parafascicular nucleus provide excitatory inputs to MSNs [14-17]. In addition, thalamic inputs to striatal cholinergic interneurons (CINs) locally control dopamine release via acetylcholine-mediated activation of nicotinic receptors on dopamine neuron terminals $[18,19]$. The combined actions of thalamostriatal pathways on MSNs and dopamine release in the striatum suggest that activation of these projections could support behavioral reinforcement. Concordantly, electrical stimulation of intralaminar thalamic nuclei supports ICSS [20]. Additionally, optogenetic stimulation of rostral intralaminar thalamic terminals in the dorsal striatum maintains operant responding in mice that were previously trained to respond for food [19]. However, it remains unknown whether stimulation of thalamostriatal terminals in the DMS is sufficient to reinforce a novel, self-initiated action.

Presynaptic G protein-coupled receptors (GPCRs) expressed on glutamatergic terminals in the striatum regulate synaptic transmission and exert substantial influence over reinforcement $[21,22]$. Agonists of the $\mathrm{G}_{\mathrm{i} / \mathrm{o}}$-coupled group II metabotropic glutamate $(\mathrm{mGlu})$ receptors $\left(\mathrm{mGlu}_{2}\right.$ and $\left.\mathrm{mGlu}_{3}\right)$ produce particularly robust presynaptic inhibition of glutamate release that is mediated by $\mathrm{mGlu}_{2}$ [23-27]. In addition, group II mGlu receptor

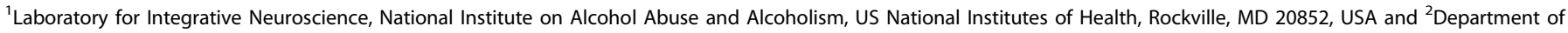
Biostatistics, Harvard T.H. Chan School of Public Health, Boston, MA 02115, USA

Correspondence: David M. Lovinger (lovindav@mail.nih.gov)

${ }^{3}$ Present address: Department of Pharmacology, Uniformed Services University of the Health Sciences, 4301 Jones Bridge Road, C2019, Bethesda, MD 20814, USA
}

Received: 29 October 2019 Revised: 10 January 2020 Accepted: 16 January 2020

Published online: 29 January 2020 
activation reduces both basal and drug-evoked extracellular dopamine levels in the striatum [28-32]. Activation of $\mathrm{mGlu}_{2}$ produces strong inhibition of thalamostriatal glutamatergic transmission onto MSNs and CINs and reduces thalamically driven, acetylcholine-mediated dopamine release [23]. Thus, $\mathrm{mGlu}_{2}$ is poised to influence behavioral reinforcement associated with thalamostriatal transmission in the dorsal striatum.

Here we evaluated operant responding for optical stimulation of thalamic terminals in the DMS. We report that mice readily press a lever for thalamostriatal stimulation without prior training for an alternative outcome or manipulation of motivational state. Consistent with known effects of $\mathrm{mGlu}_{2}$ on thalamically driven glutamate and dopamine transmission [23], group II mGlu receptor activation reduces thalamostriatal self-stimulation, whereas $\mathrm{mGlu}_{2 / 3}$ receptor blockade enhances responding. These results support a role for thalamostriatal transmission in reinforcement learning.

\section{MATERIALS AND METHODS}

\section{Animals}

Male and female mice were 5-8 weeks old at the time of surgery and 10-14 weeks old when behavioral experiments began. C57BL/ 6J mice were purchased from the Jackson Laboratory (strain 000664; Bar Harbor, ME) and arrived in the housing facility at least 1 week prior to surgery. To produce mice in which ChR2 was expressed under the control of the Vglut2 promoter, Vglut2-IRES$\mathrm{Cre}^{+/-}$mice (The Jackson Laboratory \#028863) were bred with Ai32 $2^{+/+}$mice, which contain ChR2(H134R)-EYFP downstream of a loxP-flanked STOP cassette to express ChR2 in a Cre-dependent manner (The Jackson Laboratory \#024109), to produce Vglut2IRES-Cre ${ }^{+/-}$and Vglut2-IRES-Cre ${ }^{-1-}$ mice hemizygous for the Ai32 allele [33, 34]. Animals were housed in the Fishers Lane Animal Care facility managed by the National Institute on Alcoholism and Alcohol Abuse (NIAAA). Studies were carried out in accordance with the National Institutes of Health guide for the care and use of laboratory animals and were approved by the NIAAA Animal Care and Use Committee. Mice were housed on $12 \mathrm{~h}$ light/dark cycle on ventilated racks in a temperature- and humidity-controlled room with ad libitum access to food and water, except in cases of food restriction. All experiments were carried out during the light phase.

Stereotaxic viral vector injection and optical fiber implantation Mice were anesthetized with isoflurane and placed into a stereotaxic frame (David Kopf Instruments). Craniotomy and durotomy were performed above each injection or implantation site. C57BL/6J mice were injected bilaterally with $300 \mathrm{~nL}$ AAV-ChR2 or AAV-EGFP (see Supplementary Methods) $(60 \mathrm{~nL} / \mathrm{min})$ using a Hamilton syringe with a 32-gauge needle. We targeted the anterior intralaminar nuclei of the thalamus using coordinates (relative to bregma) 1.3 posterior, 0.5 lateral, and 3.8 ventral from brain surface. For self-stimulation experiments, tips of optical fibers ( $5 \mathrm{~mm}$ long, $205 \mu \mathrm{m}$ core, $0.22 \mathrm{NA}$, with ceramic ferrule; Thorlabs) were implanted bilaterally in the DMS using coordinates (relative to bregma) anterior 0.8, 1.4 lateral, and 2.2 ventral from brain surface. Fibers were secured to the skull using Teets denture material (Co-oral-ite Dental Mfg., Diamond Springs, CA).

Optical self-stimulation task

Configurations of operant chambers and additional details are described in Supplementary Methods. Sessions began with illumination of the house light and insertion of the lever(s). Optical stimulation $(5-20 \mathrm{~Hz}, 1 \mathrm{~s}, 5 \mathrm{~ms}$ pulse width) in response to active lever presses was delivered on a fixed-ratio 1 (FR1) schedule. Sessions lasted $30 \mathrm{~min}$ with an unlimited number of reinforcements. The end of the session was signaled by extinguishing the house light and retracting the lever(s). To encourage exploration of the area immediately surrounding the active lever during early training, we performed a shaping procedure beginning 20 min into the first training session (see Supplementary Methods). Reversal learning was assessed in a subset of mice by reversing the lever that produced light delivery. Learning of the new lever-stimulation contingency was assessed over seven training sessions. Once stable pressing was observed following reversal learning, mice underwent extinction training in which an active lever press no longer produced a stimulation. Responding under extinction conditions was measured during three sessions, followed by a single reacquisition session in which we restored the active lever-stimulation contingency. No cues, priming, or other means of reinstatement were used.

Experimental timeline

Vglut2-Cre ${ }^{+/-} ; \mathrm{Ai} 32^{+/-}$mice underwent 6 days of training prior to assessment of drug effects on operant responding. Drug details are provided in Supplementary Methods. Experimental timelines for operant responding for food reinforcement and operant selfstimulation in the cohort of C57BL/6J mice expressing ChR2 in the thalamus are shown in Figs. S3a and S4a (and see Supplementary Methods).

Brain slice preparation, whole-cell patch clamp recording, and fastscan cyclic voltammetry recording

Brain slice preparation, whole-cell voltage-clamp recordings, and fast-scan cyclic voltammetry (FSCV) recordings were conducted as previously described [23] (see Supplementary Methods).

\section{Data analysis}

Data visualization and statistical analyses were performed using GraphPad Prism or R. Lever pressing across training sessions was analyzed using two-way repeated measures (RM) analysis of variance (ANOVA) or a linear mixed effects model. Session and lever were treated as within-subject factors, and genotype and viral vector differences were analyzed as between-group factors. Significant factor effects were analyzed by the indicated post hoc multiple comparisons tests. Within-subject effects of drugs or changes in stimulation rate (compared to the preceding session) were analyzed using a paired $t$-test or two-way RM ANOVA when multiple doses or conditions of the same drug or manipulation were compared. For all statistical comparisons, alpha was set at 0.05. See Supplementary Methods for additional details.

RESULTS

Optical stimulation of ChR2-expressing terminals in the DMS of Vglut2-Cre ${ }^{+/-} ; \mathrm{Ai} 32^{+/-}$mice reinforces operant responding Glutamatergic thalamic neurons that project to the dorsal striatum express the vesicular glutamate transporter Vglut2 [35]. To examine the reinforcing properties of stimulation of Vglut $^{+}$ terminals in the DMS, we expressed ChR2 in Vglut2 ${ }^{+}$projections to the striatum by crossing Vglut2-IRES-Cre ${ }^{+/-}$mice with $\mathrm{Ai} 32^{+/+}$ mice (Fig. 1a). We implanted bilateral optical fibers in the DMS of Vglut2-Cre ${ }^{+/-} ; \mathrm{Ai}_{32} 2^{+/-}$or Vglut2-Cre ${ }^{-/-} ; \mathrm{Ai}_{32} 2^{+/-}$mice (Figs. $1 \mathrm{~b}$ and $\mathrm{S} 1 \mathrm{a}, \mathrm{b})$, and then trained mice to perform a self-paced selfstimulation task. Lever presses were continuously reinforced with an optical stimulation train (20 pulses of $473 \mathrm{~nm}$ light delivered at $20 \mathrm{~Hz}$ ). Across six training sessions, optical stimulation reinforced pressing in Vglut2-Cre ${ }^{+/-} ; \mathrm{Ai} 32^{+/-}$mice, but not in Vglut2-Cre ${ }^{-/-}$; $\mathrm{Ai32} 2^{+/-}$mice (two-way RM ANOVA, session $\times$genotype interaction, $F_{(5,45)}=8.105, p<0.0001$ ) (Fig. 1c). Qualitatively, we observed that mice responded in clusters interspersed with breaks from engaging with the lever (Fig. 1d). We also observed stimulationrelated movements that emerged over the course of training (Supplementary Results, Supplementary Video 1).

We examined responses to $20-\mathrm{Hz}$ optical stimulation in brain slices to determine what synaptic mechanisms were activated. 
A

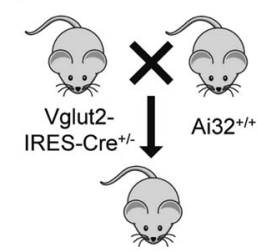

Vglut2-IRES-Cre ${ }^{+/-;}$Ai32 $2^{+-}$ Vglut2-IRES-Cre--1; $; \mathrm{Ai}^{+1 /-}$
B

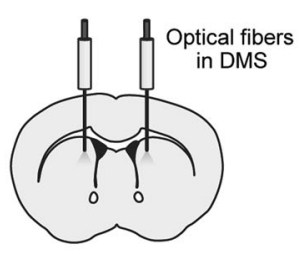

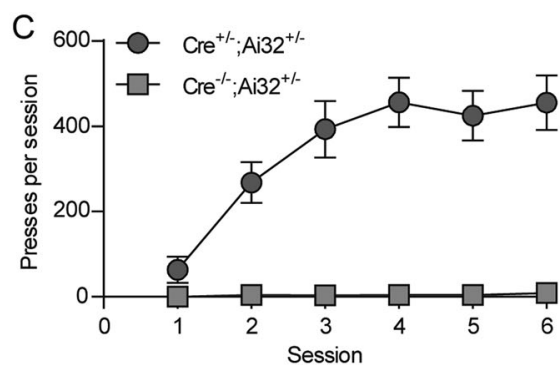

D

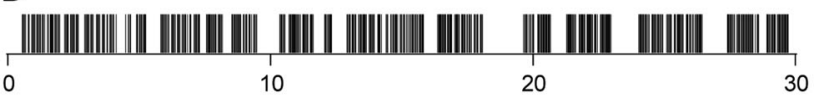

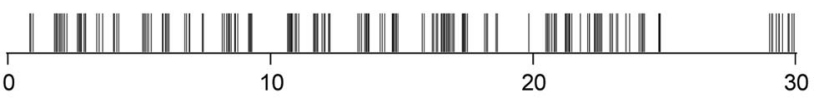

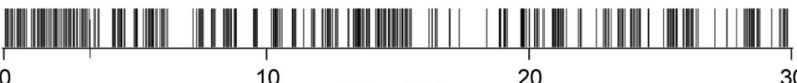

E $11111111111\|1\| 11$

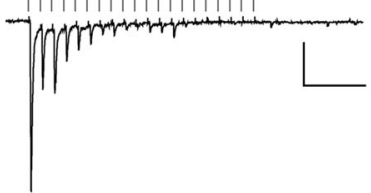

$\mathrm{F}$

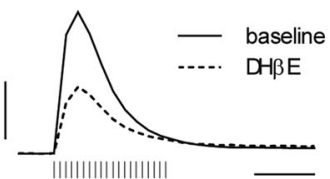

Fig. 1 Optical stimulation of Vglut2 ${ }^{+}$terminals in the DMS reinforces operant lever pressing. a Breeding scheme. b Diagram of optical fiber placement in the DMS. c Acquisition of lever pressing for 20 pulses of $20-\mathrm{Hz}$ optical stimulation in $\mathrm{Vglut}^{-}-\mathrm{Cre}^{+/} ; \mathrm{Ai}^{-1 /-}(n=7)$ and

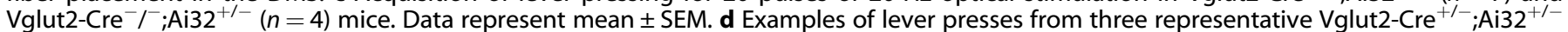
mice during acquisition session 6. Tick marks represent individual lever presses. e Representative whole-cell recording of EPSCs in a DMS medium spiny neuron evoked by 20 pulse, $20-\mathrm{Hz}$ optical stimulation. Scale bars: $100 \mathrm{pA}, 0.25 \mathrm{~s}$. f Representative FSCV traces of dopamine release measured in the DMS in response to 20 pulses of $20-\mathrm{Hz}$ optical stimulation, before and after bath application of $\mathrm{DH} \beta \mathrm{E}$ ( $1 \mu \mathrm{M})$. Scale bars: $0.5 \mu \mathrm{M}$ dopamine, $0.5 \mathrm{~s}$.

This protocol produced excitatory postsynaptic currents (EPSCs) in MSNs recorded from DMS, albeit with some failures in response to later light pulses in each train (Fig. 1e). 20-Hz stimulation also evoked dopamine release in the DMS as measured by FSCV (Fig. 1f). Dopamine release was partially blocked by the nicotinic receptor antagonist $\mathrm{DH} \beta E(1 \mu \mathrm{M})$ (Figs. 1f and S1c), suggesting that about half of dopamine release was mediated by $\mathrm{CIN}$-derived acetylcholine actions on dopamine terminals, while the remainder was attributable to direct activation of dopaminergic afferents or another indirect effect.

$\mathrm{mGlu}_{2}$ modulates responding for stimulation of $\mathrm{Vglut}^{+}$terminals in the DMS

Because $\mathrm{mGlu}_{2}$ robustly modulates striatal glutamatergic and dopaminergic transmission [23], we predicted that pharmacological manipulation of $\mathrm{mGlu}_{2}$ would alter the reinforcing properties of Vglut $^{+}$terminal stimulation in the DMS. Systemic injection of the $\mathrm{mGlu}_{2 / 3}$-preferring antagonist LY341495 prior to the selfstimulation session did not alter the number of active lever presses per session $\left(119.3 \pm 14.3 \%\right.$ of vehicle, $t_{(6)}=1.28, p=0.25$, paired $t$-test) (Fig. 2a, c, d). Conversely, LY379268 (1 or $3 \mathrm{mg} / \mathrm{kg}$ ) reduced responding (two-way RM ANOVA: main effect of treatment session (LY379268 vs. vehicle), $F_{(1,12)}=13.57, p=$ 0.0031 ) (Fig. 2b, c, e), but we did not find a significant dose $x$ treatment interaction $\left(F_{(1,12)}=0.45, p=0.51\right)$. To further understand the effects of $\mathrm{mGlu}_{2 / 3}$ activation on patterns of pressing, we quantified the number of clusters of pressing per session, the length of breaks from engaging with the lever, and within-cluster parameters including number of presses, duration, and press rate. Reduced lever pressing after $3 \mathrm{mg} / \mathrm{kg}$ LY379268 was primarily driven by an increase in the length of breaks between clusters of pressing (Fig. 2j). In DMS brain slices prepared from Vglut2-Cre ${ }^{+/-}$; $\mathrm{Ai} 32^{+/-}$mice, optically evoked dopamine release was reduced by LY379268 (100 nM); prior application of DH $\beta E$ occluded this effect, suggesting that $\mathrm{mGlu}_{2}$ exclusively attenuates dopamine release driven by glutamatergic inputs to CINs (Fig. S1d).
We trained an additional cohort of Vglut2-Cre ${ }^{+/-} ; \mathrm{Ai}_{32} 2^{+/-}$ mice to distinguish between an active lever and an inactive lever to receive a stimulation train consisting of 10 pulses at $10 \mathrm{~Hz}$ (Fig. S2a). This stimulation protocol reliably produced EPSCs in MSNs (Fig. S2b) and evoked dopamine release in brain slices (Figs. S1c and S2c). Across six training sessions, mice escalated pressing of the active lever but not the inactive lever (Fig. 3a). Two-way RM ANOVA revealed a significant session $\times$ lever interaction $\left(F_{(5,25)}=18.76, p<0.0001\right)$. To determine the specific contribution of $\mathrm{mGlu}_{2}$ to modulation of responding for stimulation of ChR2-expressing terminals in the DMS, we compared active lever presses following injection of the $\mathrm{mGlu}_{2}$-selective positive allosteric modulator BINA $(15 \mathrm{mg} / \mathrm{kg}$, i. p.) or vehicle. Like LY379268, BINA robustly decreased responding $\left(46.6 \pm 12.2 \%\right.$ of presses during vehicle session, $t_{(5)}=4.537$, $p=0.0062$, paired $t$-test) (Fig. $3 b$ ), supporting a specific role for $\mathrm{mGlu}_{2}$.

Previous studies have shown that $\mathrm{mGlu}_{2 / 3}$ activation modestly reduces operant responding for natural reinforcers [36, 37]. To assess the specificity of $\mathrm{mGlu}_{2 / 3}$ manipulations, we trained foodrestricted $\mathrm{C} 57 \mathrm{BL} / 6 \mathrm{~J}$ mice to press a lever for delivery of a food pellet (Fig. S3a, b). In contrast to the lack of effect on Vglut2 ${ }^{+}$ terminal self-stimulation, the $\mathrm{mGlu}_{2 / 3}$ antagonist LY341495 markedly reduced lever pressing for a food reinforcer to $49.7 \pm$ $5.0 \%$ of vehicle (Fig. S3C, e). Similar to previous reports in rats, LY379268 (1-3 mg/kg) modestly decreased pressing for a food reinforcer ( $1 \mathrm{mg} / \mathrm{kg}: 87.5 \pm 3.3 \%$ of vehicle; $3 \mathrm{mg} / \mathrm{kg}: 87.1 \pm 5.1 \%$ of vehicle) (Fig. S3d, e).

Optical stimulation of thalamic terminals in the DMS reinforces operant behavior

Although Vglut2 $^{+}$terminals in the dorsal striatum are typically attributed to thalamic afferents [9, 35], and little co-localization with dopamine neuron markers has been observed in the adult SNc [38], our finding that optically evoked dopamine release in the DMS of Vglut2-Cre ${ }^{+/-} ; \mathrm{Ai32}^{+/-}$mice is only partially sensitive to 

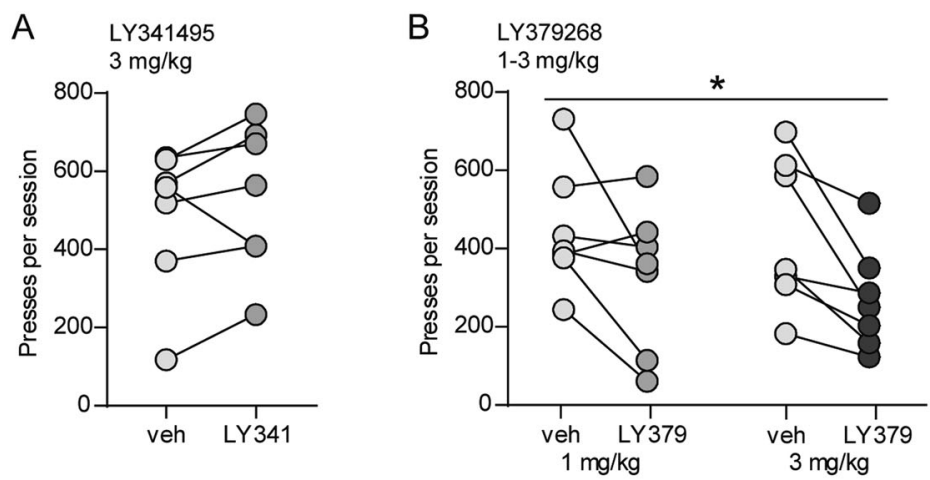

C

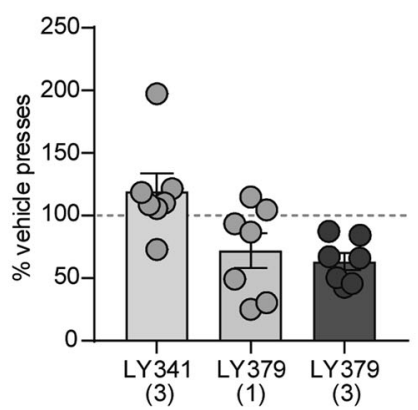

D

vehicle

E

vehicle

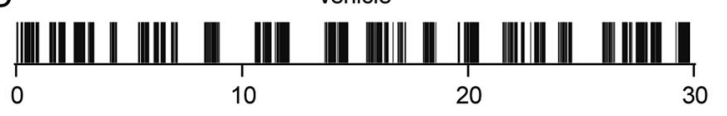

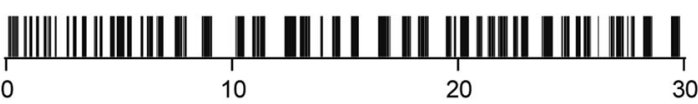
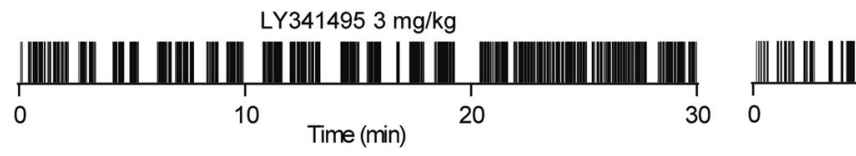

LY379268 $3 \mathrm{mg} / \mathrm{kg}$

$\mathrm{F}$

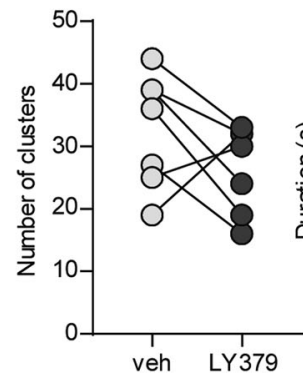

G

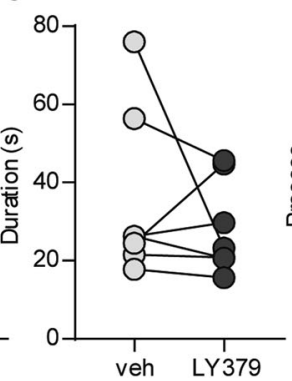

$\mathrm{H}$

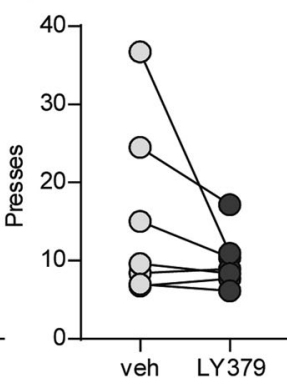

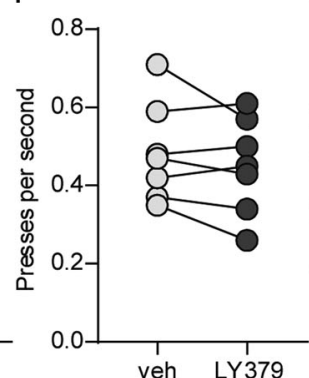

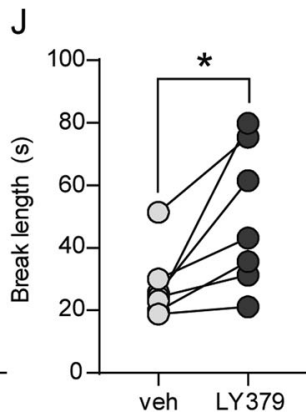

Fig. $2 \mathrm{mGlu}_{2 / 3}$ activation reduces operant responding for optical stimulation of $\mathbf{V g l u t 2}^{+}$terminals in the DMS. a, b Within-subject

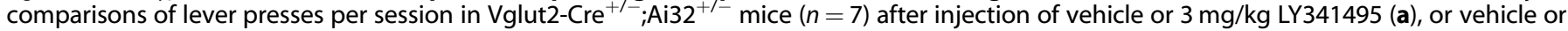
1 or $3 \mathrm{mg} / \mathrm{kg}$ LY379268 (b). For b, * indicates a main effect of treatment session (vehicle vs. LY379268; $p=0.0031$, two-way RM ANOVA). c Average lever presses per session (normalized to vehicle presses for each mouse) for each drug treatment. Bars represent mean \pm SEM, and individual data points are overlaid. Doses of each drug $(\mathrm{mg} / \mathrm{kg})$ are indicated in parentheses. d, e Examples of lever presses from a representative mouse during vehicle or drug sessions. Tick marks represent individual lever presses. $\mathbf{f}-\mathbf{j}$ Within-subject comparisons of patterns of pressing during vehicle or LY379268 $(3 \mathrm{mg} / \mathrm{kg})$ sessions. Parameters analyzed were clusters of pressing per session (f), mean duration of clusters $(\mathbf{g})$, mean number of presses per cluster (h), mean within-cluster press rate (i), and the mean length of breaks between clusters of pressing (j). For $\mathbf{j}$, ${ }^{*} t_{(6)}=3.10, p=0.0211$, paired $t$-test.

nicotinic receptor blockade suggests that ChR2 can stimulate dopamine release via direct effects on dopaminergic terminals. This is consistent with reports of broader Vglut2 expression in dopamine neurons during development $[38,39]$. In addition, the basolateral amygdala and pedunculopontine nucleus are among other regions that could contribute Vglut ${ }^{+}$glutamatergic inputs to the DMS $[33,40]$. To more selectively evaluate the reinforcing properties of thalamostriatal terminal stimulation, we virally expressed ChR2 or EGFP bilaterally in the intralaminar nuclei of the thalamus and implanted bilateral optical fibers in the DMS of C57BL/6J mice (Figs. $4 a$ and S4b, c), then trained mice in a selfpaced self-stimulation task with an active and inactive lever available (Fig. S4a). Active lever depression resulted in optical stimulation (10 pulses of blue light delivered at $10 \mathrm{~Hz}$ ). ChR2injected mice engaged in more active lever presses per session compared to EGFP-injected mice during later sessions (linear mixed effects model, $t_{(10)}=-4.028, p=0.0024$ ) (Fig. 4b, c). ChR2injected mice performed more active lever presses per session during later sessions compared to the first session $\left(t_{(193)}=-5.60\right.$, $p<0.0001)$ and engaged in fewer inactive lever presses per session than active lever presses during later sessions $\left(t_{(193)}=-11.23\right.$, $<0.0001$ ) (Fig. 4b, Supplementary Results). Among ChR2-injected mice, there was a significant lever $\times$ session interaction $\left(t_{(193)}=\right.$ $-3.64, p=0.0003$ ).

To test the influence of stimulation rate on responding for thalamostriatal stimulation, we varied the stimulation train to either 20 pulses delivered at $20 \mathrm{~Hz}$ or 5 pulses delivered at $5 \mathrm{~Hz}$ (Fig. S4d). In both cases, varying the stimulation train reduced the number of presses per session (Fig. S4e).

Brain slice electrophysiology and FSCV experiments confirmed that optical stimulation in DMS evoked both glutamate and dopamine release (Fig. 4e, f). In MSNs, the $10-\mathrm{Hz}$ stimulation train reliably produced EPSCs (Fig. 4e). Dopamine release was blocked by $\mathrm{DH} \beta \mathrm{E}$, consistent with dopamine release being driven by thalamic activation of CINs and subsequent acetylcholine actions on dopaminergic terminals (Fig. 4f) [18, 19].

Next, we evaluated the ability of mice to flexibly update rates of lever pressing in response to changes in the lever-stimulation contingency. First, we reversed the lever-stimulation contingency such that the previously inactive lever became the active lever. Upon reversal, mice decreased pressing of the formerly active lever and increased pressing of the newly active lever (two-way RM ANOVA, lever $\times$ session interaction, $F_{(7,28)}=4.554, p=0.0017$ ) (Fig. $4 \mathrm{~g}$ ). By the sixth and seventh reversal training sessions, mice 

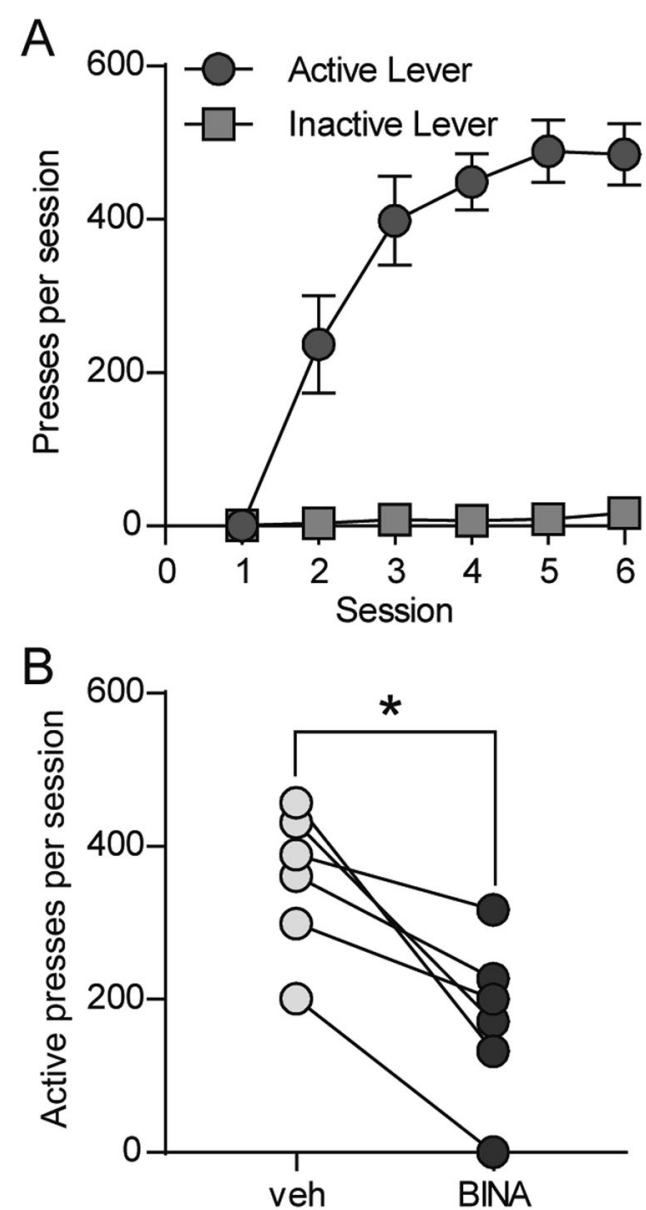

Fig. 3 The $\mathrm{mGlu}_{2}$-selective positive allosteric modulator BINA reduces operant responding for optical stimulation of Vglut2 $^{+}$ terminals in the DMS. a Active and inactive lever pressing for 10 pulses of $10-\mathrm{Hz}$ optical stimulation in Vglut2-Cre ${ }^{+/-} ; \mathrm{Ai} 32^{+/-}$ mice $(n=6)$. Data represent mean \pm SEM. b Within-subject comparison of active lever presses per session after injection of vehicle or $15 \mathrm{mg} / \mathrm{kg}$ BINA $(n=6) .{ }^{*} p=0.0062$, paired $t$-test.

pressed the newly active lever more than the previously active lever (session 6, $p=0.0022$; session 7, $p=0.0001$, Sidak's multiple comparisons test). We then evaluated responding under extinction conditions. When stimulation was no longer delivered in response to a press on the previously active lever, mice rapidly decreased responding; restoration of press-stimulation contingency during a single reacquisition session restored pressing to $52.1 \pm 7.5 \%$ of baseline levels (Fig. 4h). Across baseline, extinction, and reacquisition sessions, two-way RM ANOVA revealed a significant lever $\times$ session interaction $\left(F_{(4,16)}=23.87, p<0.0001\right)$. Post hoc comparisons demonstrated that compared with baseline pressing, mice pressed the active lever fewer times during each extinction session ( $p<0.0001$, Tukey's multiple comparisons test). When the lever-stimulation contingency was reacquired, mice pressed the active lever significantly more than during the final extinction session $(p<0.0001)$, but less than on the baseline day $(p<0.0001)$.

Group II mGlu receptors modulate lever pressing for thalamostriatal stimulation

In the same group of mice trained to press a lever for thalamostriatal stimulation, we evaluated the ability of pharmacological manipulations of group II mGlu receptors to modulate lever pressing. Pharmacological interventions were performed after the acquisition and stimulation rate manipulations but prior to reversal learning and extinction training (Fig. S4a). Injection of the group II mGlu receptor antagonist LY341495 (3 mg/kg) increased total lever presses to $209 \pm 23.7 \%$ of vehicle pressing $\left(t_{(5)}=2.666, p=0.045\right.$, paired $t$-test) (Fig. 5a, c, d). Conversely, the agonist LY379268 dose-dependently reduced responding (Fig. 5b, $C$, e). Two-way RM ANOVA revealed a significant treatment session (vehicle vs. LY379268) $\times$ dose interaction $\left(F_{(1,13)}=6.611, p=\right.$ 0.0232 ). Whereas $1 \mathrm{mg} / \mathrm{kg}$ LY379268 did not significantly reduce responding, we observed a substantial decrease in responding with $3 \mathrm{mg} / \mathrm{kg}$ ( $1 \mathrm{mg} / \mathrm{kg}$ : $78.5 \pm 10.2 \%$ of vehicle, $p=0.19 ; 3 \mathrm{mg} / \mathrm{kg}$ : $39.1 \pm 10.7 \%$ of vehicle, $p=0.0002$, Sidak's multiple comparisons test). Analysis of pressing patterns revealed that LY341495 and LY379268 had opposing effects on the number of clusters of pressing per session, with LY341495 increasing and LY379268 decreasing the number of clusters (LY341495: $t_{(5)}=5.069, p=$ 0.0039; LY379268: $t_{(5)}=3.752, p=0.0133$, paired $t$-test) (Fig. $5 f, k$ ). Similar to the effects of LY379268 in Vglut2-Cre ${ }^{+/-} ; \mathrm{Ai}_{32} 2^{+/-}$mice, the architecture of pressing within clusters was not consistently altered (Fig. 5l-n). In addition, we did not observe a significant increase in break length (Fig. 5o). Within-cluster parameters and break length were similarly unaffected by LY341495 (Fig. 5g-j).

\section{DISCUSSION}

Recent studies examining the roles of thalamostriatal projections in reinforcement learning have identified roles for discrete components of this pathway (i.e. inputs from the rostral intralaminar or parafascicular nuclei) in behavioral flexibility, operant behaviors, and incubation of drug craving $[13,19,41,42]$. Here we demonstrate that specific stimulation of thalamic terminals in the DMS supports operant conditioning in a self-paced task. Mice acquire thalamostriatal self-stimulation in the absence of predictive cues, without manipulation of motivational state (i.e. food restriction), and without prior training to respond for an alternative outcome. Our findings extend previous findings that manipulations localized to the dorsal striatum, including stimulation of MSNs or nigrostriatal dopamine release, are sufficient to reinforce a selfinitiated action [4-8].

The behavioral roles of locally regulated striatal dopamine release mediated by thalamostriatal transmission remain a major question. A recent report that $D_{1}$ receptor antagonists decrease operant responding maintained by thalamostriatal stimulation supports a role for thalamically evoked dopamine in behavioral reinforcement [19]. This is consistent with our finding that $\mathrm{mGlu}_{2}$ activation, which robustly decreases thalamically driven dopamine release [23], reduces operant responding for thalamostriatal stimulation. Thalamostriatal projections support methamphetamine seeking following forced abstinence in a $D_{1}$ receptordependent manner, further supporting the behavioral relevance of thalamic regulation of striatal dopamine transmission [41]. In Vglut2-Cre ${ }^{+/-} ; \mathrm{Ai} 32^{+/-}$mice, optical stimulation evokes dopamine release driven by $\mathrm{CIN}$-mediated activation of nicotinic receptors on dopamine neurons as well as other mechanisms, most likely direct stimulation of dopaminergic terminals. Importantly, our demonstration that mice specifically expressing ChR2 in thalamic inputs to the DMS also acquire self-stimulation behavior confirms that selective activation of thalamic glutamatergic inputs is sufficient to drive reinforcement.

Non-dopaminergic effects of glutamate released from thalamic terminals could also contribute to behavioral reinforcement. Notably, reinforcement learning driven by optogenetic stimulation of DMS MSNs does not depend on dopamine receptor activation [6]. Thalamic inputs target both $D_{1}$ - and $D_{2}$-expressing MSNs $[16,17]$ and drive excitation $[14,15]$, raising the possibility that thalamostriatal self-stimulation is at least partially supported by direct activation of MSNs. Of note, ablation of CINs surrounding the site of thalamostriatal self-stimulation only partially impairs responding, suggesting involvement of mechanisms independent 
A

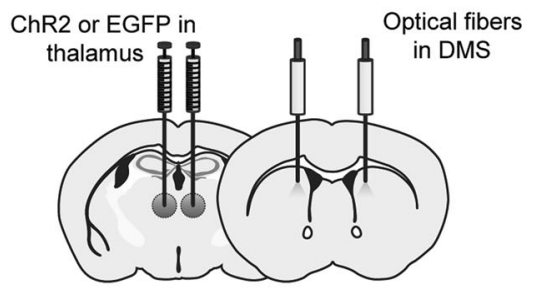

D

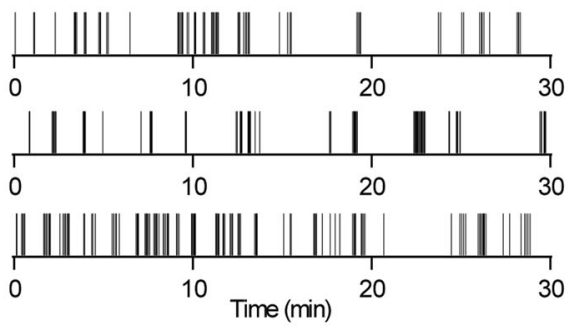

G

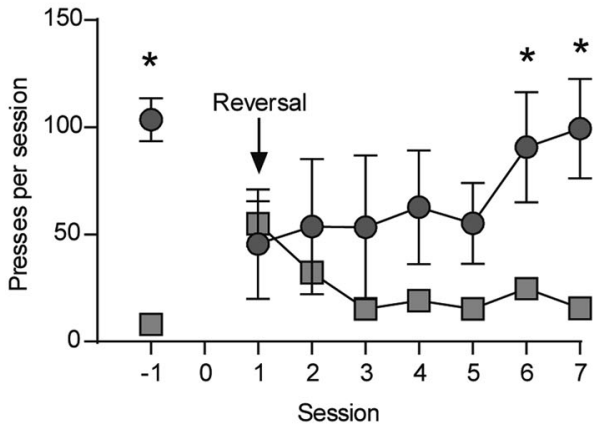

B

ChR2 in thalamus

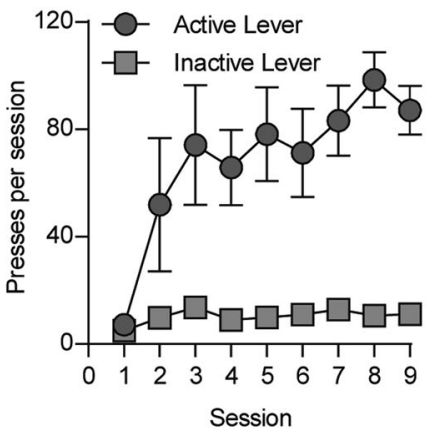

E

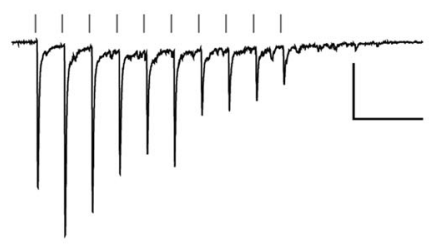

C EGFP in thalamus

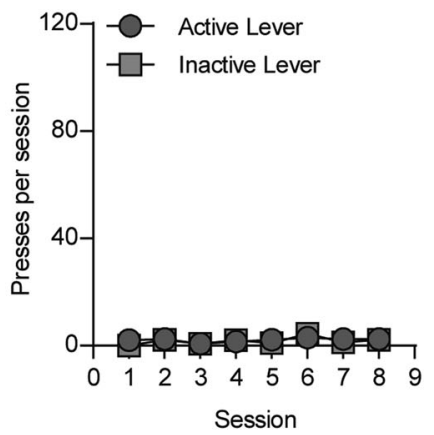

F

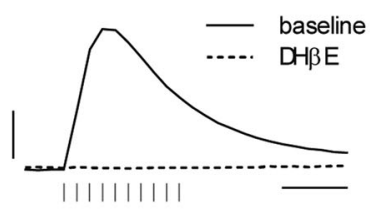

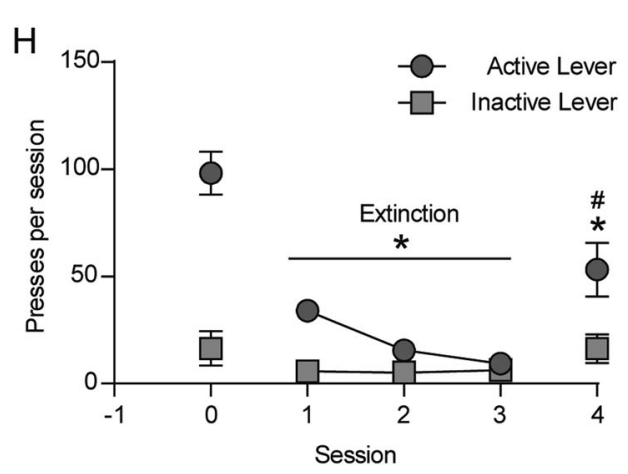

Fig. 4 Optical stimulation of thalamic terminals in the DMS reinforces operant lever pressing. a Diagram of AAV-ChR2 or AAV-EGFP injection in the anterior intralaminar nuclei of the thalamus and optical fiber placement in the DMS. $\mathbf{b}$, $\mathbf{c}$ Acquisition of lever pressing for 10 pulses of $10-\mathrm{Hz}$ optical stimulation of thalamostriatal terminals in the DMS of C57BL/6J mice expressing ChR2 (b, $n=8)$ or EGFP $(\mathbf{c}, n=4)$. d Examples of lever presses from three representative mice expressing ChR2 in thalamostriatal terminals during acquisition session 9. Tick marks represent individual lever presses. e Representative whole-cell recording of EPSCs in a DMS medium spiny neuron in response to 10 pulses of $10-\mathrm{Hz}$ optical stimulation. Scale bars: $100 \mathrm{pA}, 0.25 \mathrm{~s}$. f Representative FSCV traces of dopamine release measured in the DMS in response to 10 pulses of $10-\mathrm{Hz}$ optical stimulation, before and after bath application of $\mathrm{DH} \beta \mathrm{E}(1 \mu \mathrm{M})$. Scale bars: $0.5 \mu \mathrm{M}$ dopamine, $0.5 \mathrm{~s}$. g Lever presses at baseline and across seven sessions of reversal learning $(n=5) .{ }^{*} p<0.05$, active lever vs. inactive lever, Sidak's multiple comparisons test. $\mathbf{h}$ Lever presses at baseline, during three extinction sessions, and during one reacquisition session ( $n=5)$. ${ }^{*} p<0.05$, active lever presses during extinction/reacquisition sessions vs. baseline, Tukey's multiple comparisons test. For $\mathbf{b}, \mathbf{c}$ and $\mathbf{g}, \mathbf{h}$, data represent mean \pm SEM.

of locally evoked dopamine release [19]. Direct optogenetic activation of $\mathrm{D}_{1}$-expressing MSNs in the DMS supports reinforcement learning $[6,8]$, whereas optical stimulation of $D_{2}$-expressing MSNs promotes avoidance [6]. Thus, concurrent stimulation of excitatory inputs to both populations of MSNs could produce competing reinforcing and aversive signals that are reflected in intermittent patterns of lever engagement.

Given our findings that $\mathrm{mGlu}_{2}$ activation reduces thalamostriatal glutamatergic transmission in both MSNs and CINs, and in turn reduces locally evoked dopamine release mediated by acetylcholine [23], we predicted that pharmacological manipulation of $\mathrm{mGlu}_{2}$ would modify the reinforcing properties of light trains during our self-stimulation task. Supporting this, the $\mathrm{mGlu}_{2 / 3}$ agonist LY379268 reduced thalamostriatal self-stimulation in both Vglut2-Cre ${ }^{+/-} ; \mathrm{Ai32} 2^{+/-}$mice and C57BL/6J mice expressing ChR2 in the thalamus. In Vglut2-Cre ${ }^{+/-} ; \mathrm{Ai}_{32} 2^{+/-}$mice, this effect was mimicked by the $\mathrm{mGlu}_{2}$-selective positive allosteric modulator BINA. Moreover, our finding that the $\mathrm{mGlu}_{2 / 3}$ antagonist LY341495 increased responding suggests that $\mathrm{mGlu}_{2}$ is endogenously activated during thalamostriatal terminal stimulation and constrains the reinforcing properties of stimulation.

Our finding that $\mathrm{mGlu}_{2}$ activation constrains operant responding for thalamostriatal stimulation identifies a unique neural substrate by which $\mathrm{mGlu}_{2}$ can modify the value of a stimulus during reinforcement learning. Activation of group II mGlu receptors is known to reduce both basal and psychostimulantevoked dopamine release [28-32]. However, $\mathrm{mGlu}_{2 / 3}$ agonist administration does not reduce extracellular dopamine levels or locomotion evoked by midbrain electrical stimulation or L-DOPA administration [31]. These data are consistent with previous reports that failed to observe $\mathrm{mGlu}_{2}$ expression in nigrostriatal projections [43] and our current demonstration that nicotinic receptor blockade occludes LY379268-mediated inhibition of dopamine release in Vglut2-Cre ${ }^{+/-} ; \mathrm{Ai}^{3} 2^{+/-}$mice. Collectively, these findings are inconsistent with $\mathrm{mGlu}_{2}$ reduction of dopamine release via direct actions on dopaminergic terminals. It is likely that $\mathrm{mGlu}_{2}$ acting on glutamatergic inputs to CINs, and possibly MSNs, underlies the dampened reinforcing properties of 
A

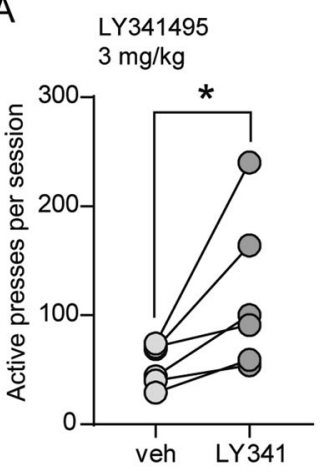

B

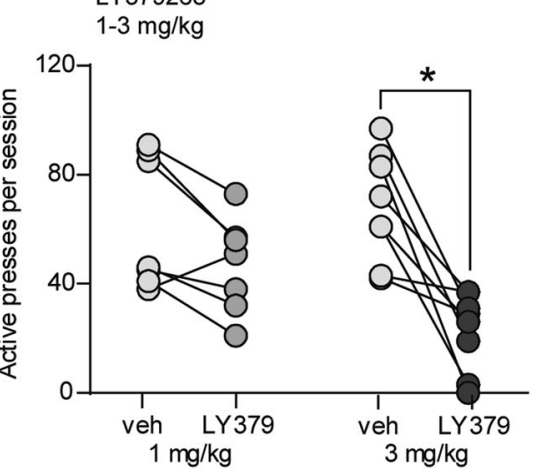

C

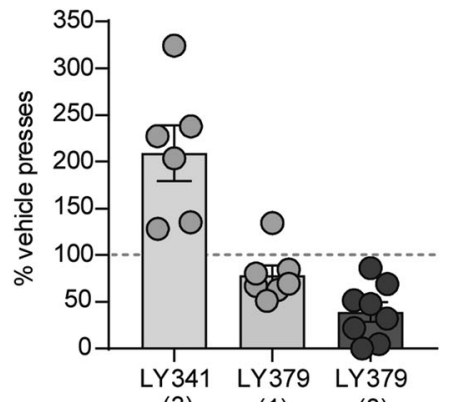

(3)

(1)

(3)
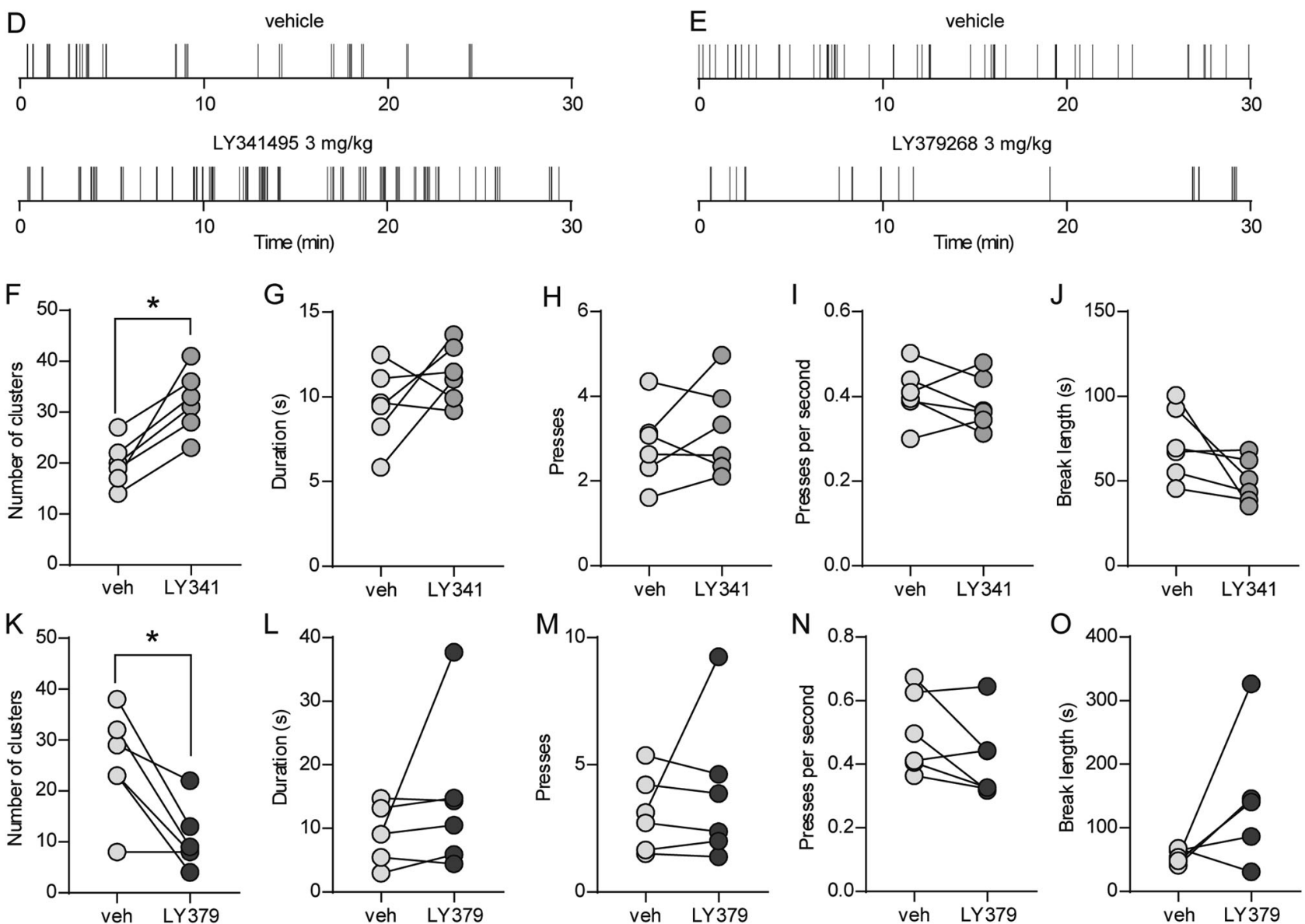

Fig. $5 \mathbf{m G l u}_{2 / 3}$ activity constrains operant responding for thalamostriatal stimulation. a, b Within-subject comparisons of lever presses per session in C57BL/6J mice expressing ChR2 in thalamostriatal terminals $(n=6-8)$ after injection of vehicle or $3 \mathrm{mg} / \mathrm{kg} \mathrm{LY} 341495(\mathbf{a})$ or 1 or $3 \mathrm{mg} / \mathrm{kg}$ LY379268 (b). ${ }^{*} p<0.05$, paired $t$-test (a) or Sidak's multiple comparisons test (b). c Average active lever presses per session (normalized to vehicle presses for each mouse) for each drug treatment. Bars represent mean \pm SEM, and individual data points are overlaid. Doses of each drug $(\mathrm{mg} / \mathrm{kg})$ are indicated in parentheses. d, e Examples of lever presses from a representative mouse during vehicle or drug sessions. Tick marks represent individual lever presses. f-o Within-subject comparisons of patterns of pressing during vehicle vs. $3 \mathrm{mg} / \mathrm{kg} \mathrm{LY} 341495$ $(\mathbf{f}-\mathbf{j})$ or vehicle vs. $3 \mathrm{mg} / \mathrm{kg}$ LY379268 (k-o) sessions. Parameters analyzed were clusters of pressing per session (f, $\mathbf{k})$, mean duration of clusters $(\mathbf{g}, \mathbf{I})$, mean number of presses per cluster $(\mathbf{h}, \mathbf{m})$, mean within-cluster press rate $(\mathbf{i}, \mathbf{n})$, and the mean length of breaks between clusters of pressing $(\mathbf{j}, \mathbf{o})$. For $\mathbf{f}, \mathbf{k},{ }^{*} p<0.05$, paired $t$-test.

Vglut2 ${ }^{+}$or thalamostriatal terminal stimulation following administration of LY379268 or the mGlu 2 -selective PAM BINA. However, $\mathrm{mGlu}_{2}$ (and possibly $\mathrm{mGlu}_{3}$ ) actions in downstream circuit elements that support operant responding could also contribute to these effects.

Consistent with the ability to decrease drug-enhanced extracellular dopamine levels, $\mathrm{mGlu}_{2 / 3}$ activation decreases self-administration of psychoactive drugs including cocaine, amphetamines, nicotine, and alcohol [29, 32, 37, 44-52]. However, the ability of these receptors to constrain reinforcement appears dependent on the nature of the reinforcer. In previous studies, $\mathrm{mGlu}_{2 / 3}$ agonists reduced responding for natural reinforcers such as sucrose, although such findings are inconsistent and typically involve higher doses than are required to decrease responding for psychoactive drugs [21, 36, 37]. We observed a modest decrease in responding for palatable food following LY379268 administration. Notably, administration of the 
$\mathrm{mGlu}_{2 / 3}$ antagonist LY341495 produced opposing effects on responding for thalamostriatal stimulation (increased responding) vs. food reinforcement (decreased responding). Similar to effects on thalamostriatal self-stimulation, previous studies have shown that LY341495 administration or genetic deletion of $\mathrm{mGlu}_{2}$ increases selfadministration of reinforcing drugs such as alcohol, cocaine, and heroin [53-56]. These incongruent effects might reflect differential engagement of circuitry modulated by mGlu receptors depending on the stimulus. Future studies measuring thalamostriatal activity and striatal dopamine dynamics during reinforcement learning are necessary to determine the engagement of this pathway during acquisition of operant responding for various outcomes, including natural reinforcers and psychoactive drugs.

\section{FUNDING AND DISCLOSURES}

This work was supported by NIAAA Division of Intramural Clinical and Biological Research ZIA AA000416 (to D.M.L.) and NIH grant K99 AA025403 (to K.A.J.). The authors declare no conflicts of interest.

\section{ACKNOWLEDGEMENTS}

We thank all members of the Lovinger laboratory for helpful discussions and Guoxiang Luo for assistance with genotyping. We thank Dr. David Kupferschmidt for technical advice and comments on the manuscript.

\section{AUTHOR CONTRIBUTIONS}

K.A.J. and D.M.L. conceived the project and wrote the manuscript. Y.M. and L.V. performed and analyzed FSCV experiments. K.A.J. performed and analyzed whole-cell electrophysiology and behavioral experiments. G.C.L. contributed technical expertise and performed statistical analysis of behavioral data. L.V., G.C.L., and Y.M. provided feedback on the manuscript.

\section{ADDITIONAL INFORMATION}

Supplementary information accompanies this paper at (https://doi.org/10.1038/ s41386-020-0626-y).

Publisher's note Springer Nature remains neutral with regard to jurisdictional claims in published maps and institutional affiliations.

\section{REFERENCES}

1. Graybiel AM, Grafton ST. The striatum: where skills and habits meet. Cold Spring Harb Perspect Biol. 2015;7:a021691.

2. Phillips AG, Carter DA, Fibiger HC. Dopaminergic substrates of intracranial selfstimulation in the caudate-putamen. Brain Res. 1976;104:221-32.

3. Prado-Alcala R, Wise RA. Brain stimulation reward and dopamine terminal fields. I. Caudate-putamen, nucleus accumbens and amygdala. Brain Res. 1984;297: 265-73.

4. Rossi MA, Sukharnikova T, Hayrapetyan VY, Yang L, Yin HH. Operant selfstimulation of dopamine neurons in the substantia nigra. PLoS ONE. 2013;8: e65799

5. Ilango A, Kesner AJ, Keller KL, Stuber GD, Bonci A, Ikemoto S. Similar roles of substantia nigra and ventral tegmental dopamine neurons in reward and aversion. J Neurosci. 2014:34:817-22.

6. Kravitz AV, Tye LD, Kreitzer AC. Distinct roles for direct and indirect pathway striatal neurons in reinforcement. Nat Neurosci. 2012;15:816-8.

7. Vicente AM, Galvao-Ferreira P, Tecuapetla F, Costa RM. Direct and indirect dorsolateral striatum pathways reinforce different action strategies. Curr Biol. 2016;26:R267-269.

8. Lalive $A L$, Lien $A D$, Roseberry $T K$, Donahue $C H$, Kreitzer $A C$. Motor thalamus supports striatum-driven reinforcement. Elife. 2018;7:e34032

9. Smith Y, Galvan A, Ellender TJ, Doig N, Villalba RM, Huerta-Ocampo I, et al. The thalamostriatal system in normal and diseased states. Front Syst Neurosci. 2014;8:5.

10. Hunnicutt BJ, Jongbloets BC, Birdsong WT, Gertz KJ, Zhong H, Mao T. A comprehensive excitatory input map of the striatum reveals novel functional organization. Elife. 2016:5:e19103
11. Hintiryan H, Foster NN, Bowman I, Bay M, Song MY, Gou L. et al. The mouse cortico-striatal projectome. Nat Neurosci. 2016;19:1100-14.

12. Balleine BW, O'Doherty JP. Human and rodent homologies in action control: corticostriatal determinants of goal-directed and habitual action. Neuropsychopharmacology 2010;35:48-69.

13. Bradfield LA, Hart G, Balleine BW. The role of the anterior, mediodorsal, and parafascicular thalamus in instrumental conditioning. Front Syst Neurosci. 2013;7:51.

14. Lacey CJ, Bolam JP, Magill PJ. Novel and distinct operational principles of intralaminar thalamic neurons and their striatal projections. J Neurosci. 2007:27:4374-84.

15. Ellender TJ, Harwood J, Kosillo P, Capogna M, Bolam JP. Heterogeneous properties of central lateral and parafascicular thalamic synapses in the striatum. J Physiol. 2013;591:257-72.

16. Huerta-Ocampo I, Mena-Segovia J, Bolam JP. Convergence of cortical and thalamic input to direct and indirect pathway medium spiny neurons in the striatum. Brain Struct Funct. 2014;219:1787-1800.

17. Doig NM, Moss J, Bolam JP. Cortical and thalamic innervation of direct and indirect pathway medium-sized spiny neurons in mouse striatum. J Neurosci 2010;30:14610-8.

18. Threlfell S, Lalic T, Platt NJ, Jennings KA, Deisseroth K, Cragg SJ. Striatal dopamine release is triggered by synchronized activity in cholinergic interneurons. Neuron 2012;75:58-64.

19. Cover KK, Gyawali U, Kerkhoff WG, Patton MH, Mu C, White MG, et al. Activation of the rostral intralaminar thalamus drives reinforcement through striatal dopamine release. Cell Rep. 2019;26:1389-98 e1383.

20. Clavier RM, Gerfen CR. Intracranial self-stimulation in the thalamus of the rat Brain Res Bull. 1982;8:353-8.

21. Johnson KA, Lovinger DM. Presynaptic G protein-coupled receptors: gatekeepers of addiction? Front Cell Neurosci. 2016;10:264.

22. Atwood BK, Lovinger DM, Mathur BN. Presynaptic long-term depression mediated by Gi/o-coupled receptors. Trends Neurosci. 2014;37:663-73.

23. Johnson KA, Mateo $\mathrm{Y}$, Lovinger DM. Metabotropic glutamate receptor 2 inhibits thalamically-driven glutamate and dopamine release in the dorsal striatum. Neuropharmacology. 2017;117:114-23.

24. Kupferschmidt DA, Lovinger DM. Inhibition of presynaptic calcium transients in cortical inputs to the dorsolateral striatum by metabotropic $\mathrm{GABA}(\mathrm{B})$ and mGlu2/ 3 receptors. J Physiol. 2015;593:2295-310.

25. Lovinger DM, McCool BA. Metabotropic glutamate receptor-mediated presynaptic depression at corticostriatal synapses involves mGLuR2 or 3. J Neurophysiol. 1995;73:1076-83.

26. Kahn L, Alonso G, Robbe D, Bockaert J, Manzoni OJ. Group 2 metabotropic glutamate receptors induced long term depression in mouse striatal slices. Neurosci Lett. 2001;316:178-82.

27. Martella G, Platania P, Vita D, Sciamanna G, Cuomo D, Tassone A. et al. Enhanced sensitivity to group II mGlu receptor activation at corticostriatal synapses in mice lacking the familial parkinsonism-linked genes PINK1 or Parkin. Exp Neurol. 2009;215:388-96.

28. Hu G, Duffy P, Swanson C, Ghasemzadeh MB, Kalivas PW. The regulation of dopamine transmission by metabotropic glutamate receptors. J Pharm Exp Ther. 1999:289:412-6.

29. Kim JH, Austin JD, Tanabe L, Creekmore E, Vezina P. Activation of group II mGlu receptors blocks the enhanced drug taking induced by previous exposure to amphetamine. Eur J Neurosci. 2005;21:295-300.

30. D'Souza MS, Liechti ME, Ramirez-Nino AM, Kuczenski R, Markou A. The metabotropic glutamate $2 / 3$ receptor agonist LY379268 blocked nicotine-induced increases in nucleus accumbens shell dopamine only in the presence of a nicotine-associated context in rats. Neuropsychopharmacology. 2011;36:2111-24.

31. Pehrson AL, Moghaddam B. Impact of metabotropic glutamate $2 / 3$ receptor stimulation on activated dopamine release and locomotion. Psychopharmacology. 2010;211:443-55

32. Bauzo RM, Kimmel HL, Howell LL. Interactions between the mGluR2/3 agonist LY379268, and cocaine on in vivo neurochemistry and behavior in squirrel monkeys. Pharm Biochem Behav. 2009:94:204-10.

33. Vong L, Ye C, Yang Z, Choi B, Chua S,Jr., Lowell BB. Leptin action on GABAergic neurons prevents obesity and reduces inhibitory tone to POMC neurons. Neuron. 2011;71:142-54.

34. Madisen L, Mao T, Koch H, Zhuo JM, Berenyi A, Fujisawa S. et al. A toolbox of Credependent optogenetic transgenic mice for light-induced activation and silencing. Nat Neurosci. 2012;15:793-802.

35. Fremeau RT,Jr., Voglmaier S, Seal RP, Edwards RH. VGLUTs define subsets of excitatory neurons and suggest novel roles for glutamate. Trends Neurosci. 2004;27:98-103.

36. Kufahl PR, Martin-Fardon R, Weiss F. Enhanced sensitivity to attenuation of conditioned reinstatement by the mGluR 2/3 agonist LY379268 and increased 
functional activity of mGluR $2 / 3$ in rats with a history of ethanol dependence. Neuropsychopharmacology. 2011;36:2762-73.

37. Justinova Z, Le Foll B, Redhi GH, Markou A, Goldberg SR. Differential effects of the metabotropic glutamate $2 / 3$ receptor agonist LY379268 on nicotine versus cocaine self-administration and relapse in squirrel monkeys. Psychopharmacology. 2016;233:1791-1800.

38. Poulin JF, Caronia G, Hofer C, Cui Q, Helm B, Ramakrishnan C. et al. Mapping projections of molecularly defined dopamine neuron subtypes using intersectional genetic approaches. Nat Neurosci. 2018;21:1260-71.

39. Trudeau LE, Hnasko TS, Wallen-Mackenzie A, Morales M, Rayport S, Sulzer D. The multilingual nature of dopamine neurons. Prog Brain Res. 2014;211:141-64.

40. Assous M, Dautan D, Tepper JM, Mena-Segovia J. Pedunculopontine glutamatergic neurons provide a novel source of feedforward inhibition in the striatum by selectively targeting interneurons. J Neurosci. 2019;39:4727-37.

41. Li X, Witonsky KR, Lofaro OM, Surjono F, Zhang J, Bossert JM. et al. Role of anterior intralaminar nuclei of thalamus projections to dorsomedial striatum in incubation of methamphetamine craving. J Neurosci. 2018;38:2270-82.

42. Kato S, Fukabori R, Nishizawa K, Okada K, Yoshioka N, Sugawara M, et al. Action selection and flexible switching controlled by the intralaminar thalamic neurons. Cell Rep. 2018;22:2370-82.

43. Testa CM, Friberg IK, Weiss SW, Standaert DG. Immunohistochemical localization of metabotropic glutamate receptors mGluR1a and mGluR2/3 in the rat basal ganglia. J Comp Neurol. 1998;390:5-19.

44. Liechti ME, Lhuillier L, Kaupmann K, Markou A. Metabotropic glutamate 2/3 receptors in the ventral tegmental area and the nucleus accumbens shell are involved in behaviors relating to nicotine dependence. J Neurosci. 2007:27:9077-85.

45. Sidhpura N, Weiss F, Martin-Fardon R. Effects of the mGlu2/3 agonist LY379268 and the mGlu5 antagonist MTEP on ethanol seeking and reinforcement are differentially altered in rats with a history of ethanol dependence. Biol Psychiatry. 2010;67:804-11.

46. Augier E, Dulman RS, Rauffenbart C, Augier G, Cross AJ, Heilig M. The mGluR2 positive allosteric modulator, AZD8529, and cue-induced relapse to alcohol seeking in rats. Neuropsychopharmacology. 2016;41:2932-40.

47. Dhanya RP, Sheffler DJ, Dahl R, Davis M, Lee PS, Yang L, et al. Design and synthesis of systemically active metabotropic glutamate subtype-2 and -3
(mGlu2/3) receptor positive allosteric modulators (PAMs): pharmacological characterization and assessment in a rat model of cocaine dependence. J Med Chem. 2014;57:4154-72.

48. Dhanya RP, Sidique S, Sheffler DJ, Nickols HH, Herath A, Yang L, et al. Design and synthesis of an orally active metabotropic glutamate receptor subtype-2 (mGluR2) positive allosteric modulator (PAM) that decreases cocaine selfadministration in rats. J Med Chem. 2011;54:342-53.

49. Jin X, Semenova S, Yang L, Ardecky R, Sheffler DJ, Dahl R. et al. The mGluR2 positive allosteric modulator BINA decreases cocaine self-administration and cueinduced cocaine-seeking and counteracts cocaine-induced enhancement of brain reward function in rats. Neuropsychopharmacology. 2010;35:2021-36.

50. Li X, D'Souza MS, Nino AM, Doherty J, Cross A, Markou A. Attenuation of nicotinetaking and nicotine-seeking behavior by the mGlu2 receptor positive allosteric modulators AZD8418 and AZD8529 in rats. Psychopharmacology. 2016;233: 1801-14.

51. Crawford JT, Roberts DC, Beveridge TJ. The group II metabotropic glutamate receptor agonist, LY379268, decreases methamphetamine self-administration in rats. Drug Alcohol Depend. 2013;132:414-9.

52. Justinova Z, Panlilio LV, Secci ME, Redhi GH, Schindler CW, Cross AJ. et al. The novel metabotropic glutamate receptor 2 positive allosteric modulator, AZD8529, decreases nicotine self-administration and relapse in squirrel monkeys. Biol Psychiatry. 2015;78:452-62.

53. Zhou Z, Karlsson C, Liang T, Xiong W, Kimura M, Tapocik JD, et al. Loss of metabotropic glutamate receptor 2 escalates alcohol consumption. Proc Natl Acad Sci USA. 2013;110:16963-8.

54. Morishima $Y$, Miyakawa T, Furuyashiki T, Tanaka $Y$, Mizuma $H$, Nakanishi $S$. Enhanced cocaine responsiveness and impaired motor coordination in metabotropic glutamate receptor subtype 2 knockout mice. Proc Natl Acad Sci USA. 2005;102:4170-5.

55. Yang HJ, Zhang HY, Bi GH, He Y, Gao JT, Xi ZX. Deletion of type 2 metabotropic glutamate receptor decreases sensitivity to cocaine reward in rats. Cell Rep. 2017;20:319-32.

56. Gao JT, Jordan CJ, Bi GH, He Y, Yang HJ, Gardner EL. et al. Deletion of the type 2 metabotropic glutamate receptor increases heroin abuse vulnerability in transgenic rats. Neuropsychopharmacology. 2018;43:2615-26. 